\title{
Impact of New Shift Models for Doctors Working at a German University Hospital for Gynaecology and Obstetrics Four Years After Implementation. Can They Meet the European Working Time Directive Without Increasing Costs?
}

\author{
Auswirkungen neuer Dienstzeitmodelle für Ärzte einer deutschen Universitäts-Frauenklinik vier Jahre \\ nach der Einführung - können die Anforderungen der Europäischen Arbeitszeitrichtlinie eingehalten werden, \\ ohne die Kosten zu erhöhen?
}

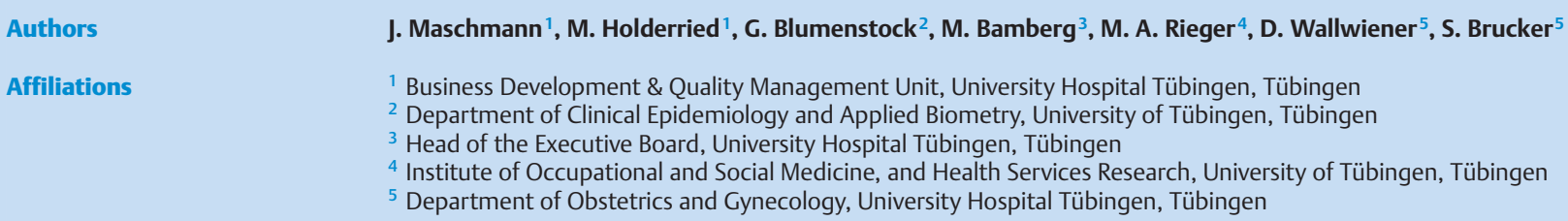

Key words
gynecology
EWTD
doctors
shift model
university hospital
Schlüsselwörter
Frauenheilkunde
Ärzte
Arbeitszeitmodell
- Universitätsklinik

received 6.2.2013

revised $\quad 7.4 .2013$

accepted 26.4.2013

\section{Bibliography}

DOI http://dx.doi.org/

$10.1055 / \mathrm{s}-0032-1328751$

Geburtsh Frauenheilk 2013; 73:

713-719 ๑ Georg Thieme

Verlag KG Stuttgart · New York ISSN 0016-5751

\section{Correspondence \\ Dr. Jens Maschmann,}

Dr. med., MBA

University Hospital Tübingen

Business Development

\& Quality Management Unit

Hoppe-Seyler-Straße 6

72076 Tübingen

jens.maschmann@

med.uni-tuebingen.de

\section{Abstract}

$\nabla$

Background: The impact of the European Working Time Directive and subsequent collective wage agreements for doctors from 2006 onwards were substantial. So far, no systematic evaluation of their application in Germany has been performed. We evaluated the impact four years after implementation of new shift models in a University Hospital for Gynaecology and Obstetrics (UHGO).

Methods: A new shift model was created together with doctors of Tübingen UHOG in 2007 and implemented in 2008. Documentation of working hours has hence been done electronically. Adherence to the average weekly working time limit (AWTL) and the maximum of $10 \mathrm{~h}$ daily working time (10 h-dwt) was evaluated, as well as staffing costs in relation to case-weight points gathered within the German DRG (diagnosis related groups) System.

Results: Staff increased from a mean of 44.7 full time equivalent (FTE) doctors in 2007 to 52.5 FTE in 2009, 50.8 in 2010, and 54.5 in 2011. There was no statistically significant difference of the monthly staff expenditures per case-weight between the years 2009 or 2010 vs. 2007. 2011, however, was significantly more expensive than 2007 ( $p=0.02$ ). The internal control group (five other departments of the university hospital) did not show an increase during the same period. AWTL were respected by 90,96 , and $98 \%$ in 2009,2010 , and 2011, respectively. Of all shifts $10 \mathrm{~h}$-dwt was exceeded by $7.4 \%$ in $2009,1.3 \%$ in 2010 , and $2.6 \%$ in 2011, with significant differences between 2009 and both, 2010 and 2011 $(p<0.001)$, and between 2010 and 2011 $(\mathrm{p}=0.02)$.

Discussion: AWTL and $10 \mathrm{~h}$-dwt could be continuously respected quite well after implementation of the new shift model without increasing the

\section{Zusammenfassung \\ $\nabla$}

Hintergrund: Die Vorgaben der Europäischen Arbeitszeitrichtlinie und deren Spezifizierung im Tarifvertrag für Ärzte im Jahr 2006 haben sich deutlich auf die Dienstplangestaltung ausgewirkt. Bislang wurden die Einhaltung der Vorgaben sowie die Auswirkung der notwendigen Änderungen an den Dienstmodellen nicht systematisch untersucht. Die vorliegende Arbeit untersucht die Auswirkungen eines an die rechtlichen Vorgaben angepassten neuen Dienstmodells in einer deutschen Universitätsfrauenklinik (UFK) 4 Jahre nach Umstellung.

Methodik: Ein neues Dienstmodell wurde gemeinsam mit den betroffenen Ärzten der UFK Tübingen 2007 entwickelt und 2008 eingeführt. Seither wird die Dienstplanung und -dokumentation elektronisch vorgenommen, was unter anderem Auswertungen zur Einhaltung der durchschnittlichen Wochenarbeitszeit (dWAZ) und zur Einhaltung der 10-Stunden-Tageshöchstarbeitszeitgrenze (10 h-TAZ) ermöglicht. Zudem wurden die Personalkosten für Ärzte in Relation zu den erbrachten Relativgewichtspunkten nach dem deutschen Fallpauschalen (G-DRG) Katalog aus der stationären Patientenversorgung vor und nach Umstellung des Dienstmodells untersucht. Ergebnisse: Die Anzahl an Ärzten stieg von einem Jahresmittel von 44,7 Vollkräften (VK) in 2007 vor Einführung des neuen Dienstmodells auf 52,5 VK in 2009, 50,8 VK in 2010 und 54,5 VK in 2011 an. Die monatlichen Personalkosten pro Relativgewichtspunkt waren zwischen den Jahren 2007 gegenüber 2009 oder 2010 statistisch nicht zu unterscheiden. 2011 war jedoch signifikant teurer als 2007 ( $p=0,02)$. Die interne Kontrollgruppe, die aus 5 anderen Kliniken des Universitätsklinikums bestand, zeigte im gleichen Zeitverlauf diesbezüglich keinen Unterschied. Die dWAZ wurde 2009 zu 90\%, 2010 zu 96\% und 2011 zu 
cost/earnings ratio for the first two years. However, in 2011 the ratio increased significantly $(\mathrm{p}=0.02)$.
98\% eingehalten. Die Überschreitungen der $10 \mathrm{~h}$-TAZ bezogen auf alle vergebenen Schichten betrugen 7,4\% in 2009, 1,3\% in 2010 und 2,6\% in 2011, wobei sich die Werte zwischen 2009 und sowohl 2010 als auch 2011 signifikant unterschieden $(\mathrm{p}<0,001)$, sowie zwischen 2010 und $2011(\mathrm{p}=0,02)$.

Diskussion: Die Einhaltung der dWAZ und der $10 \mathrm{~h}$-TAZ konnte durchgehend sehr gut mit dem neuen Dienstmodell gewährleistet werden, ohne dass sich das Verhältnis von Personalkosten zu Relativgewichtspunkten in den ersten beiden Jahren nach Umstellung im Vergleich zu 2007 veränderte. Lediglich 2011 stieg dieser Quotient signifikant an $(\mathrm{p}=0,02)$.

\section{Background}

$\nabla$

Working times for doctors at hospitals are an ongoing topic of debate. In Germany, weekly working hours of more than 50-60 h were reported $[1,2]$, whereas in the US weekly working hours were restricted to $80 \mathrm{~h}$ for residents $[3,4]$. The trend towards more female doctors and a general change in the attitude of younger doctors concerning their work-life-balance $[5,6]$ challenges the working patterns in hospitals. University hospitals are especially concerned as they have to balance the three aspects of patient care, research, and teaching. In the field of Gynaecology and Obstetrics significantly longer daily working times at German university hospitals as compared to other hospitals were observed [7], reaching an average of $10 \mathrm{~h} /$ day.

The strike for better working conditions of German doctors working at university hospitals in spring 2006 led to a new collective wage agreement (TV-Ä university hospitals) becoming effective on November 1st, 2006. Similar wage agreements were found for other hospitals in Germany, too. Two months later, the regulations of the European Working Time Directive (EWTD) [8] became mandatory in Germany. Together, both conditions had the following impact on working time for hospital doctors at university hospitals: 1) weekly working time of 42 hours for a full time employee, 2) average weekly working time limit (AWTL) between 42 and 48 hours, 3) individual agreement to increase AWTL up to 54 hours under certain conditions (so called optout), 4) maximum daily working time of 10 hours (10 h-dwt), and 5) extension of this limit up to 12 hours under certain conditions.

The Executive Board of the University Hospital Tübingen therefore decided to design new shift models for doctors with the aim to achieve both, compliance to the EWTD and stability of labour costs. In this report we will answer the question if these two targets could be reached on a medium term perspective.

\section{Methods \\ $\nabla$}

In collaboration with the head of the University Hospital for Gynaecology and Obstetrics (UHGO) as well as the responsible senior and junior doctors for staffing and shift planning, a project team considered carefully possible weaknesses of the pre-existing shift model in 2007. This was also done in the university hospitals for General, Visceral, and Transplantation Surgery, Neurosurgery and Anaesthesiology. All four were considered as pilot departments before other departments became involved. A detailed description of the methodology used can be found elsewhere [9].
The pre-existing model was characterized by a single shift for all doctors lasting from 7:30 to $16: 45 \mathrm{~h}$ during the week (ending 15:00 h on Fridays) followed by three on-call shifts (one senior and two junior doctors). On weekends the $24 \mathrm{~h}$ on-call shifts had full shift segments between 8:00-10:00 h for ward rounds. The delivery rooms were covered with three shifts consecutively throughout the week.

The UHGO has its proper building with 107 beds, 6 operating theatres ( 4 for inpatients, one for outpatients, and one for obstetrics), 6 delivery rooms, and an elaborated structure of outpatient clinics. Per year, approximately 8300 inpatients and 19500 outpatients are being treated, 2800 babies delivered, and the specialisation in gynaeco-oncology results in 700 primary mamma carcinomas treated. The designed shift model is therefore rather complex and the result is shown in $\bullet$ Fig. 1. The main changes were as follows:

\section{2 hour shifts}

The pre-existing three shift model for the delivery rooms was changed to a two shift model on weekends and holidays with a shift length of $12 \mathrm{~h} 30 \mathrm{~min}$. including breaks. This allowed a reduction of the frequency of weekend shifts as foreseen in $\S 7 \mathrm{sec}-$ tion 3 TV-Ä university hospitals. In some very specialised outpatient clinics and on one gynaecology ward long shifts lasting $11 \mathrm{~h}$ $30 \mathrm{~min}$ and $12 \mathrm{~h} 0 \mathrm{~min}$, respectively, were introduced, too.

\section{Late shift}

For the gynaecology wards a late shift (12:30-21:00 h) was established that was run by one senior and two junior doctors to allow a prolonged operating theatre time until 20:30 h. This prolongation of the operating theatre hours was an adaptation to the pre-existing reality. Due to the high demand for complex operations there was a regular excess of the former operating theatre hours up to 3-4 hours, leading to violations of the former working times.

\section{Adapted shift lengths}

For the wards and the outpatient clinics adapted shift lengths between $8.4 \mathrm{~h}$ and $10 \mathrm{~h}$ plus breaks were introduced. On weekends a full shift from 9:30-18:00 h was established to cover the time with the heaviest workload, followed by an on-call shift both of which were run by one senior and one junior doctor.

Based on these modifications all doctors could be asked whether they wanted to work more than 48 hours/week (so called optout). The survey was done after introduction of the new shift model. The number of doctors needed to run the new shift model was calculated a priori with a supposed average of $50 \mathrm{~h} /$ week per doctor. Due to the prolonged operating theatre hours and the new operating theatre for outpatients it was assumed that more 


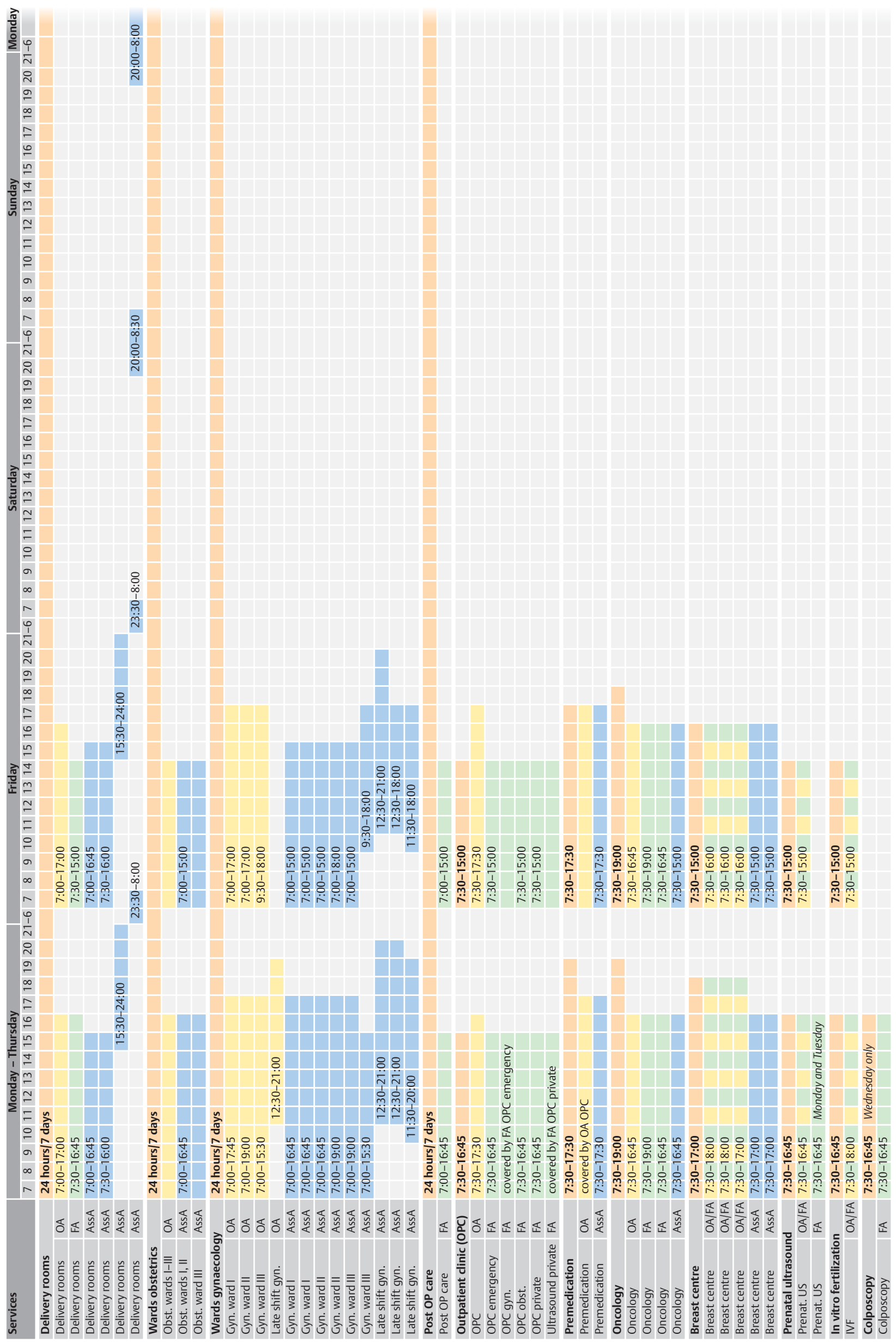




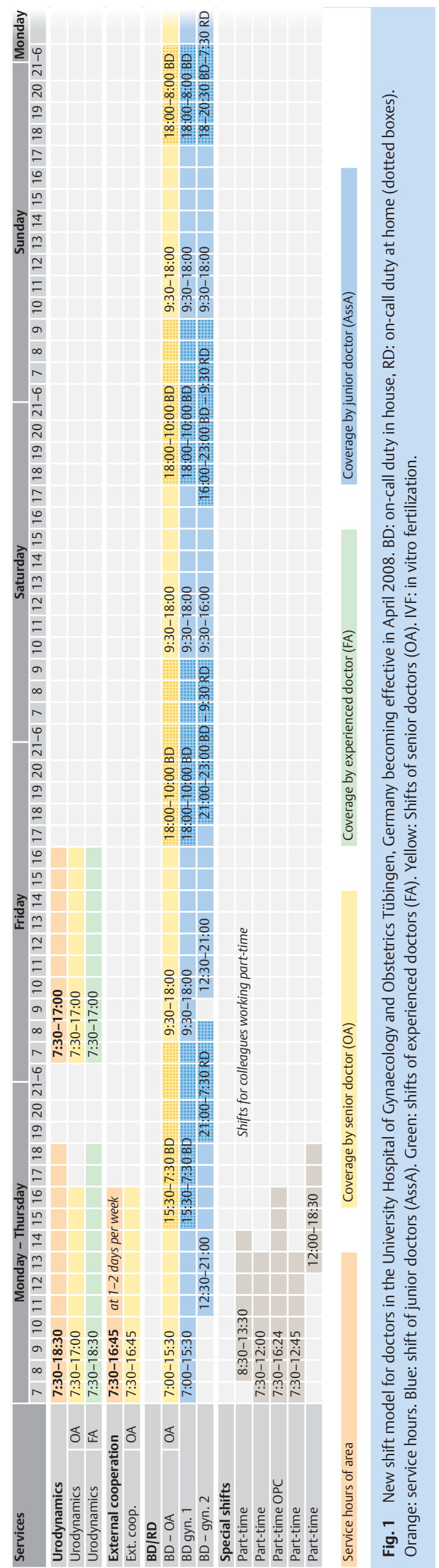

patients could be treated and thus financing the extra staff should be achievable.

Research and especially teaching are integrated elements within the shift model. For research, we reduced the number of physicians (i.e. the academic medical staff) a priori by $10 \%$ reflecting the $10 \%$ proportion of funding from the medical faculty for academic research to the overall budget of the University Hospital of Gynaecology and Obstetrics. This means that the shift model reflects the time needed for patient treatment and teaching and in part, research activities.

Statistics: AWTL, $10 \mathrm{~h}-\mathrm{dwt}$, and opt-out data are reported as numbers of subjects with denominators and percentages. Monthly staff costs of both junior and senior doctors before and after implementation of the new shift model, and percentages of surpassed $10 \mathrm{~h}$ daily working time in 2009, 2010, and 2011 were evaluated by analysis of variance (ANOVA). When ANOVA indicated an overall difference, multiple comparisons were performed using the Tukey-Kramer method. To correct for the planned increase in surgical capacity, the costs were calculated relative to the case-weights gained by the department within the German Diagnosis Related Groups (DRG) system. Caseweights are a typical element of a DRG system as they represent the economic severity of an inpatient case. The DRG-catalogue lists a specific case-weight for every DRG ranging for example in 2011 from 0.502 for an uncomplicated vaginal delivery (DRG O60D) to 7.088 for a radical vulvectomy (DRG N01A). Multiplying the case-weight with the base-rate (2985.50 Euro in 2011) one gets the bill the hospital can claim the health insurance company of the patient. Therefore, the more patients or the more complex patients were treated within the UHGO, the higher were the earnings to compensate e.g. for higher staffing costs. For comparison of possible effects of the new shift models, a control group was used consisting of the departments of Neurology, Radiooncology, Ophthalmology, Ear-, Nose-, and Throat- (ENT), and Dermatology whose shift models were unaltered between 2007 and 2011. The statistical analysis was done with JMP 8.0.2 (SAS Institute, Cary, NC).

\section{Results}

A calculated number of 53.1 FTE-doctors were necessary to cover all services of the UHGO after introduction of the new shift model. However, not all increase in staff was attributable to the regulations of the EWTD as an additional operating theatre for day surgery as well as prolonged shifts to run one operating theatre until 20:30 h had to be covered with staff, too. In 200744.7 FTEdoctors were working in the UHGO, increasing in 2009 to a mean of 52.5 FTE-doctors, 50.8 in 2010, and 54.5 in 2011. Concurrently, $17 \%$ (9/54) of doctors were working part-time in 2009 , rising to $23 \%(15 / 66)$ in 2010 , and to $25 \%(15 / 61)$ in 2011.

Opt-out

In $200975 \%$ (30/40) of doctors voted for opt-out, $74 \%$ (39/53) did so in 2010, and 61\% (30/49) voted for opt-out in 2011.

AWTL

In 200936 out of 40 doctors (90\%) were able to respect their AWTL rising to 51/53 (96\%) in 2010, and $48 / 49$ (98\%) in 2011, as shown in $\odot$ Fig. 2. 


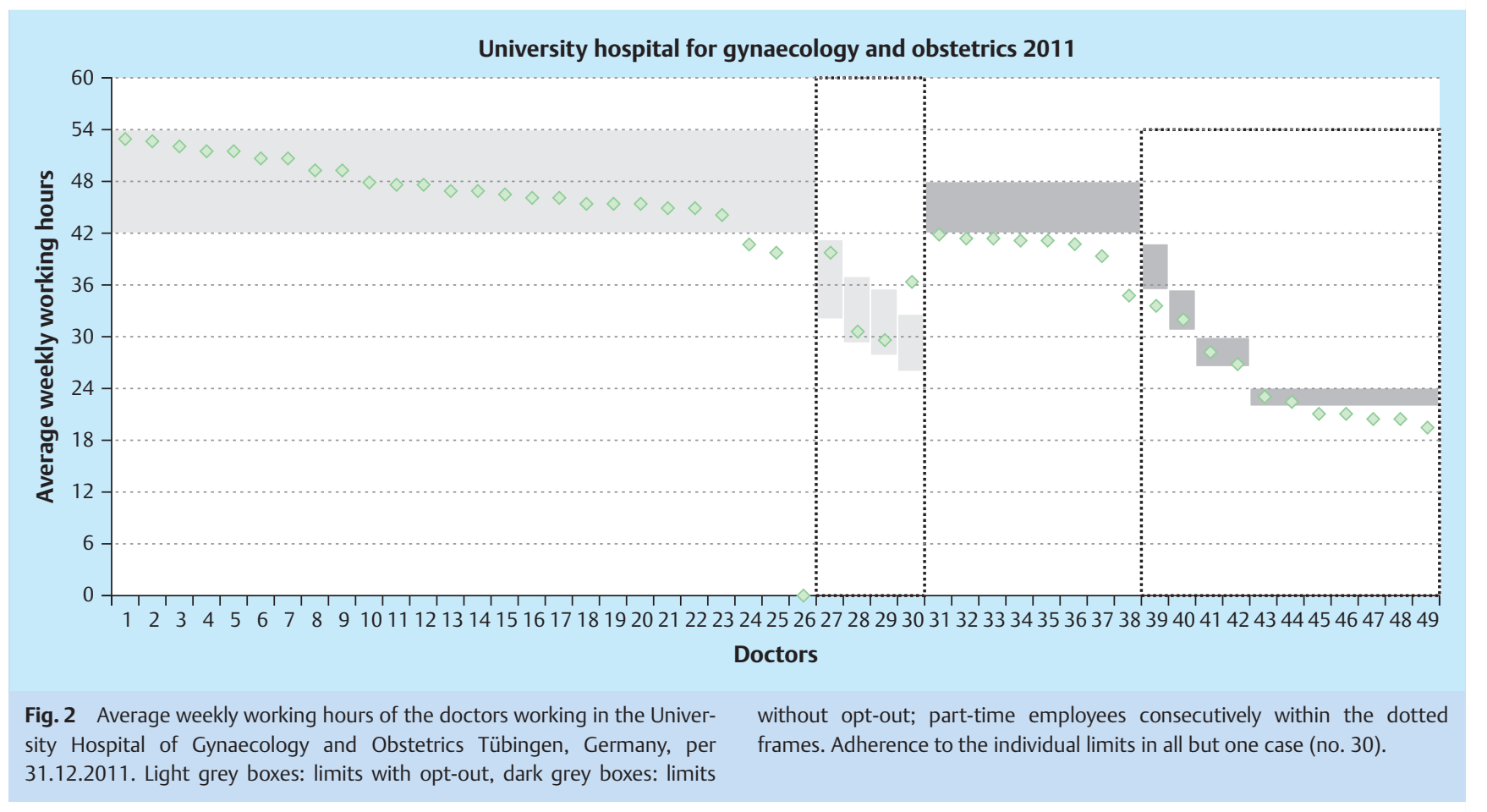

\section{$10 \mathrm{~h}-\mathrm{dwt}$}

The proportions of shifts that surpassed the $10 \mathrm{~h}$-threshold in relation to all shifts with a maximum length of ten hours were $7.4 \%$ (524 out of 7112) in 2009, 1.2\% (103 out of 8241) in 2010, and $2.6 \%$ (238 out of 9092) in 2011 ( Fig. 3), with significant differences between 2009 and 2010 as well as 2009 and 2011 $(p<0.001$, Tukey-Kramer), and between 2010 and 2011 $(\mathrm{p}=0.02$, Tukey-Kramer post-hoc test $)$.

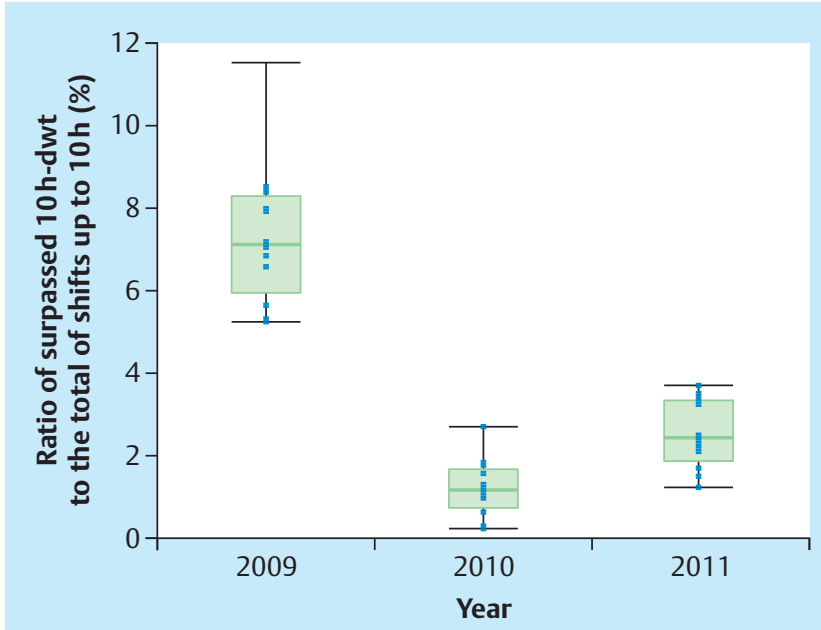

Fig. 3 Percentage of surpassed $10 \mathrm{~h}$ daily working time ( $10 \mathrm{~h}-\mathrm{dwt}$ ) in relation to the total of shifts with a length up to $10 \mathrm{~h}$ for each month of the years 2009 to 2011 (after implementation of the new shift model). Significant decline from 2009 to both, 2010 and 2011. Significant increase from 2010 to 2011.

\section{Staff expenditures}

As shown in 0 Fig. 4 the average monthly staff expenditures per case-weight for the years 2007, 2009, 2010, and 2011 were 593.04 Euro, 643.95 Euro, 603.30 Euro, and 677.79 Euro, respectively. There was no statistically significant difference between the years 2009 or 2010 vs. 2007, yet 2011 was significantly more expensive than 2007 ( $p=0.02$, Tukey-Kramer). In absolute terms, staff expenditures for doctors rose from a mean of 384136.20 Euro per month in 2007 to 476899.20 Euro in 2009, 450069.60 Euro in 2010, and 504193.10 in 2011. This represents a 31.3\%

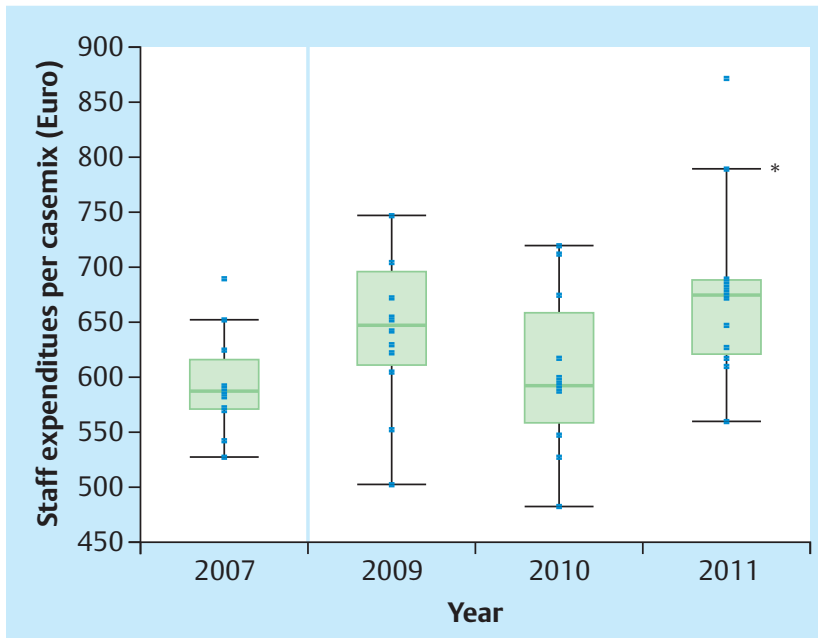

Fig. 4 Monthly staff expenditures per caseweight point before (2007) and after the implementation of the new shift model (2009-2011) in the University Hospital of Gynaecology and Obstetrics Tübingen. Only 2011 was significantly more expensive as compared to $2007(p=0.02)$, whereas 2010 as well as 2009 vs. 2007 were not. 
raw increase from 2007 to 2011 (27.3\% when corrected for the four percent increase in tariffs during that time). Likewise, performance increased from a mean of 650.3596 case-weight points per month in 2007 to 746.0169 in 2009, 750.5321 in 2010, and 752.5701 in 2011 (15.7\% increase 2007 to 2011).

In contrast, the control group had staff expenditures per caseweight of 687.74 Euro in 2007, 710.87 Euro in 2009, 731.69 Euro in 2010, and 796.78 Euro in 2011, the differences being non-significant $(\mathrm{p}=0.34)$.

\section{Discussion}

$\nabla$

With this study we have shown for the first time how a German UHGO was able to comply with the regulations of the EWTD and the subsequent wage agreement. The increase of 7.8 FTE (2007 vs. 2009) in medical staff required to run the new shift model was unambiguous, yet the compliance to AWTL as well as $10 \mathrm{~h}-\mathrm{dwt}$ were already very good in the first full year after implementation (2009: 90 and 92.6\%, respectively) and could even be improved over the years (2011: 98 and 97.4\%, respectively). As pointed out the increase in staff was in a large part attributable to extended operating theatre hours and a new day surgery theatre.

The resulting increase in patients being treated along with rising case-weights during the observation period have kept the ratio of staffing costs for doctors to case-weight points stable. When comparing the staffing costs per case-weight point of the UHGO with the internal control group, no differences were evident. This effect has also been shown for the University Hospital for Neurosurgery in Tübingen [10] indicating that the strategy of adapting the new shift models to the needs of operating hours for patient care and thus allowing a higher turnover was successful.

In the UHGO, only the year 2011 was strikingly more expensive than the previous period probably because the average number of doctors in 2011 (54.5 FTE) was highest of all post-implementation years and, on the contrary, the year-to-year increase in caseweight points per month was only moderate (2.0380). The estimated 53.1 FTE required to run the new shift model seemed to be rather well confirmed by the evaluation. Interestingly, the number of opt-out votes declined between 2009 and 2011 from 75 to $61 \%$, a phenomenon that could also be observed in the Department of Anaesthesiology of the University Hospital Tübingen [11]. An explanation might be the increasing wish to limit weekly working hours to a subjectively acceptable level. When looking at the rising proportion of doctors working in part time $17 \%$ in 2009 to $25 \%$ in 2011) this becomes very obvious as eleven out of 19 of the non opt-out voters were working in part time in 2011 (○ Fig. 2). However, so far no investigation of doctors' motivation to opt-out has been performed in Germany. In the context of decreasing opt-out votes and rising proportions of doctors working in a part-time scheme it is remarkable that the compliance to the regulations of the ETWD has again been increased in the UHGO of Tübingen. However, both effects may have also influenced the relatively pronounced increase in staff costs per case-weight point in 2011 because more doctors (persons) were employed thus rising staffing costs disproportionately.

As shown elsewhere shift models with more than only one single shift seemed to be more effective in preventing violations of the 10 h-dwt [9] which has now been demonstrated over a threeyear post-implementation period.

However, there are several study limitations. Firstly, in this exploratory study no gynaecology and obstetric internal control group was available. The pool of five other independent Departments (Ear-, Nose-, and Throat-, Dermatology, Radiooncology, Neurology and Ophthalmology) with so far no alteration of shift models should nevertheless serve as a reasonable control group. Secondly, this is only a single site observation and one might speculate whether the results are reproducible in external UHGO departments. Thirdly, we can only present cost and revenue data on a before and after basis. The former paper-based documentation of individual working times in the pre-implementation period made it impossible to report on AWTD and $10 \mathrm{~h}$-dwt by 2007. Fourthly, there were several highly experienced senior gynaecologists who were employed with so called off-tariff contracts. In Germany, the EWTD applies in general for all doctors that are employed by a hospital and not only for those in post-graduate training. It is sometimes difficult for highly specialised senior doctors to comply with the working time regulations, especially in a university hospital setting where working tasks cover patient care, research, and students' education. We can thus only speculate how their AWTL and $10 \mathrm{~h}$-dwt were respected.

In fact, we are now able to present robust administrative data that are neither based on surveys nor on subjective descriptions allowing us to improve and adapt the shift model to changing needs of both, doctors and hospital alike. The methodology presented here can serve as a basis for interventional studies in other hospitals.

The concern of decreasing caseloads and therefore less training of residents in Gynaecology and Obstetrics due to EWTD regulations was expressed several times. Comparing the caseloads before and after implementation of the $80 \mathrm{~h}$-workweek, Short et al. found no differences for gynaecological cases, yet obstetric cases in residents' training declined after implementation [12]. Smith found no negative effects on resident technical expertise [13]. We did so far not analyse possible changes in caseload for residents in Tübingen or control for prolongation of residency programmes but this is impending. At present, we have no hint that the new shift model had a negative impact on these issues in our institution.

We hope that this report adds some more objective information to the discussion whether and how the EWTD regulations do affect clinicians and hospitals alike.

\section{Practical implications}

$\nabla$

- Adherence to the EWTD and the regulations of the collective wage agreement for doctors working at German university hospitals can be achieved by carefully adapting new shift models to the needs of both, patient care and doctors working at an UHGO.

- The necessary increase in doctors and thus staffing costs can be balanced by an increased patient turnover resulting in more revenues. That way, the proportion of staff costs per caseweight point in the German DRG-system remains stable.

\section{Acknowledgement \\ $\nabla$}

We would like to thank all the members of the project team that designed and implemented the new shift model at UHGO, namely Mr. Rau, Mrs. Gesche, Mrs. Hack, Dr. Wilke, Dr. Dehner, Mr. Wütz-Botsch, Dr. Abele, Dr. Rothmund, Dr. Hübner, Dr. Hoffmann and Dr. Walter. 


\section{Conflict of Interest}

None.

\section{References}

1 Köhler S, Baumann L, Kaiser R. Arbeitszeiten Hessischer Krankenhausärzte seit 2001 - Ergebnisse repräsentativer Befragungen der Landesärztekammer. Hessisches Ärzteblatt 2007; 68: 738-741

2 Rosta J. Arbeitszeit der Krankenhausärzte in Deutschland. Dtsch Arztebl 2007; 104: A2417-A2423

3 Antiel RM, Thompson SM, Reed DA et al. ACGME duty-hour recommendations - a national survey of residency program directors. $\mathrm{N}$ Engl J Med 2010; 363: e12

4 Nasca TJ, Day SH, Amis jr. ES; for the ACGME Duty Hour Task Force. The new recommendations on duty hours from the ACGME Task Force. N Engl J Med 2010; 363: e3

5 Dettmer S, Kuhlmey A, Scholz S. Gehen oder bleiben? Dtsch Arztebl 2009; 107: A30-A31

6 Institut für Qualität und Evaluationsmessung. Ergebnisbericht der Mitgliederbefragung, Marburger Bund 2010. Analyse der beruflichen Situation der angestellten und beamteten Ärzte in Deutschland. Landau: IQME; 2011
7 Kloß L, Klapp BF, Quarcoo D et al. Die Arbeitsbelastungen und Arbeitszufriedenheit Fachbereich Gynäkologie und Geburtshilfe - eine Arbeitsanalyse. Zbl Arbeitsmed 2010; 60: 86-91

8 EU-Richtlinie des EU-Parlamentes und des Rates über bestimmte Aspekte der Arbeitszeitgestaltung. 2003/88/EG. 18.11.2003, 2003

9 Maschmann J, Holderried M, Blumenstock $G$ et al. Umsetzung von tarifrechtlich und Arbeitszeitgesetz-konformen Dienstmodellen im ärztlichen Dienst am Universitätsklinikum Tübingen. Gesundh ökon Qual manag 2012; 17: 151-158

10 Maschmann J, Holderried M, Blumenstock G et al. New shift models for doctors in a large German University Neurosurgery Department: how they comply with the European Working Time Directive 3 years after implementation. Acta Neurochir (Wien) 2012; 154: 1935-1940

11 Maschmann J, Holderried M, Blumenstock G et al. Neues Dienstzeitenmodell für Ärzte in der Anästhesie. Eine Analyse 3 Jahre nach Implementierung. Anaesthesist 2012; 61: 941-947

12 Short A, Rogers S, Magann E et al. The 80-hour workweek restriction: How are $\mathrm{OB} / \mathrm{GYN}$ resident procedure numbers affected? J Matern Fetal Neonatal Med 2006; 19: 801-806

13 Smith RP. Resident technical experience in obstetrics and gynecology before and after implementation of work-hour rules. Obstet Gynecol 2010; 115: 1166-1171 